\title{
Shakespeare em Xangai: a propósito de um Hamlet da Garagem
}

FRANCISCO LUÍS PARREIRA ${ }^{1}$

Título: Hamlet. Texto: William Shakespeare. Tradução: José Blanc de Portugal, revista por José Henrique Neto. Encenação, concepção plástica e dramaturgia: Carlos J. Pessoa. Interpretação: Ana Palma, Beatriz Godinho, Emanuel Arada, José Henrique Neto, Maria João Vicente, Miguel Mendes, Nuno Nolasco e Nuno Pinheiro. Cenografia e figurinos: Sérgio Loureiro. Música, desenho e operação de som: Daniel Cervantes. Desenho e operação de luz: Nuno Samora. Produção: Teatro da Garagem. Direcção de produção: Maria João Vicente. Produção e comunicação: Carolina Mano. Local e data de estreia: Teatro Duanjun, Xangai, 14 de Setembro de 2016.

\section{[...] for the eye sees not itself}

But by reflection, by some other things.

WILLIAM SHAKESPEARE, Julius Caesar

A Huashan Lu, onde se situa a Academia de Teatro de Xangai, é uma das vias pelas quais, idealmente, poderíamos delimitar a ocidente aquela zona da cidade conhecida como Concessão Francesa, aberta em meados do século XIX para evitar (como as suas congéneres norte-americana e japonesa) que os abismos da miséria chinesa permanecessem monopólio exclusivo dos canhões britânicos. Sobre o fundamento da administração «extraterritorial», em breve o outrora insignificante entreposto costeiro se modificaria em metrópole inundada por banqueiros, soldados da fortuna, missionários, expatriados e, acima de tudo, do lumpen nativo fugido ao despotismo manchu - caldo projectado no romantismo colonial, assíduo da infâmia, sob o eufemismo de «cidade internacional». Já bem entrado o século xx, foi no inferno da Concessão Francesa que prosperou a mitologia apocalíptica de Xangai: a corrupção, o gangsterismo, os bordéis de la beauté exotique, as carretas matinais recordadas por J. G. Ballard, daqui nativo, que recolhiam das ruas, às dezenas, os chineses mortos durante a noite pela fome ou o ópio colonial. Não por acaso, foi também, pela mesma altura, o berço intelectual do marxismo

1 Este artigo resulta de uma estadia apoiada pela Fundação Oriente. 
chinês - mas até isso, agora, parece inconcebível. A Concessão é uma vasta extensão de tranquilas alamedas, alpendradas, na maior parte, de plátanos frondosos e estranhamente exoneradas do peso humano que se anteciparia na cidade mais populosa do mundo. Calam os jardins exuberantes, no recesso dos quais pontificam as villas modernistas, agora como hotéis ou edifícios públicos; no vislumbre das passagens e serventias secundárias, insinuam-se apertadas malhas de compactos habitacionais, ali, onde outrora pejavam os chikumen, os tugúrios do proletariado chinês, cujas relíquias foram agora cometidas à restauração e ao lazer sumptuário. Por vezes, nos cruzamentos, a vida fugidia é restituída aos seus direitos; sobressaltam-nos as motocicletas apinhadas, a oficina sombria, os escaparates da fruta. Em relvados largos, mãos idosas testam a dura brisa da reforma e disciplinam, nas grandes alturas, os papagaios de papel. Mais além, um estaleiro recente administra a cratera de um quarteirão dizimado, ou surte de repente o alto viaduto do trânsito congestionado; enfim, abrem-se as amplas perspectivas e, no longe empedernido, a todo o redor, perfilam-se esses cambiantes estandartes da vida populosa e antigravitacional, os arranha-céus de Xangai.

Em nenhum ponto se reconhece a China antecipada e antiquíssima; e, porém, em toda a parte, subsiste uma validação profética do Oriente: tudo é ilusão, nada é permanente. É possível que nem os arranha-céus de anteontem estejam cá amanhã. Xangai absolveu-se dos deveres da História, tudo foi entregue à caducidade. Em nenhuma outra cidade do mundo será o desgaste e o refazer das formas tão voraz, tão entregue às ideias condutoras que, ainda vagas e insondáveis, parecem extraídas ao futuro para virem comprazer um desejo de irreconhecimento que aturde em cada esquina. A revogação final do passado, outrora procurada pela Revolução Cultural, é hoje prosseguida pelos meios infinitamente mais subtis do capital; a vida da cidade mede-se na rarefacção crescente da propriedade e dos seus direitos, nos planos de realojamento massivo, nas remodelações pensadas à escala do quarteirão, e a isso corresponde a abstracção crescente do algoritmo urbano. A continuidade intuitiva da experiência urbana foi suspensa: o espaço não é já a sua condição formal, mas o seu único obstáculo; o tempo foi dissipado na absoluta autonomia do Evento. Todas as representações se entrecruzam e colidem, e nenhuma parece apta a domesticar este mundo heteróclito sobre cujos fundamentos nenhum mistério, senão o da tranquilidade das ruas, tem ocasião em que repousar ou História em que se plasmar. Este esforço imenso de libertação não tem paralelo na experiência da cidade 
europeia, para a qual, desde a Idade Média, a tensão entre um universalismo nacional (ou romano, no caso italiano) e a particularidade cultural representou a linha agregadora na dispersão da sua experiência, a sua distinção e a sua vaidade. A vaidade de Xangai, como a de Tóquio ou do Cairo, é outra: funda-se no colapso dos universalismos e das divisões duradouras que eles inscreveram no chão da História: a nação e o mundo, o socialismo e o capitalismo, o local e o global. Trata-se de cidades já sem nação e sem local, puras unidades informacionais de um código que já não diz respeito à História da Terra, que já só aponta à sinalização do espaço extraterrestre e se constitui como arrogante perturbação da entrópica noite exterior. Porém, a falência dos universalismos é a oportunidade para a universalidade autêntica. «Universalidade» não significa aqui o «c'est partout comme ici» leibniziano, mas a máxima aglomeração das diferenças, de outro modo invisíveis a não ser pela lógica mesma da sua coexistência, saindo a campo para o jogo livre e horizontal da sua afirmação, chamando a si o carácter excessivo das coisas que vivem o momento da sua primeira irrupção e não recusam veicular aquelas forças que não aproveitarão, que não poderão ser contidas em nenhuma forma.

Que assim seja apenas traz à luz o sistema de correspondências que ampara uma singularidade de Xangai: a de aspirar ser a nova pátria de Shakespeare (ou, para sermos exactos, 沙士比亚, Shashibiya). Está já atestada a aptidão de Shakespeare à transumância, e não será necessário recordar de que modo a idolatria alemã, depois de Herder e de Goethe, quase remeteu ao plano da conspiração histórica o facto de Shakespeare não ter nascido alemão. Atracção semelhante exerce agora o Bardo sobre o espírito chinês, permeando a sua vida cultural com os prestígios que só outro ocidental, ainda hoje e por razões bem conhecidas, pôde reclamar: Karl Marx. Nas escolas e universidades chinesas, proliferam os centros de pesquisa shakespeariana; o Bardo culmina os currículos e é estímulo de uma competição intra-universitária anual; é foco de uma revista especializada, a Shashibiya Yanjiu (Estudos Shakespearianos), objecto de uma sociedade nacional com várias réplicas provinciais, motivo de festivais dramáticos e conferências internacionais. Uma consulta da Chinese National Knowledge Infrastructure (em linha) mostra que, entre 2009 e 2015, Shashibiya originou mais de duzentas e cinquenta dissertações de mestrado ou doutoramento, e uma busca comparativa de «Hamlet» na World Shakespeare Bibliography Online atesta que, na última década, entre literatura académica e produções teatrais, se escreveu mais sobre 


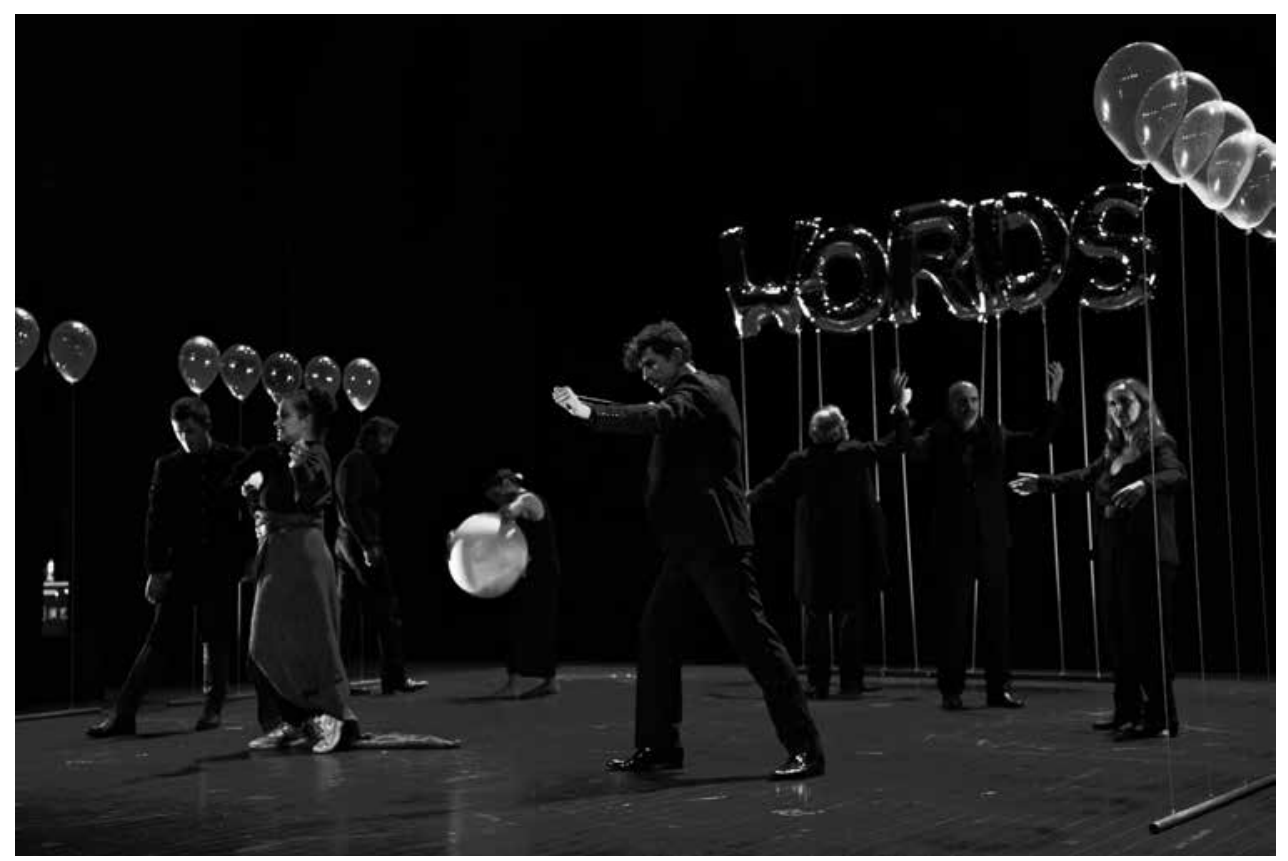

HAMLET, DE WILLIAM SHAKESPEARE, ENC. CARLOS J. PESSOA, TEATRO DA GARAGEM, 2016 (NUNO NOLASCO, ANA PALMA, EMANUEL ARADA, BEATRIZ GODINHO, NUNO PINHEIRO, JOSÉ HENRIQUE NETO, MIGUEL MENDES, MARIA JOÃO VICENTE), [F] ACADEMIA DE TEATRO DE XANGAI

o príncipe da Dinamarca em mandarim do que em qualquer outra língua, a inglesa incluída. Que dizer? Xangai parece decerto pátria mais apropriada que Stratford-upon-Avon, na qual (para nos exprimirmos de modo piedoso) estamos sempre condenados ao desânimo daquele bardólatra americano que, no conto de Henry James «The Birthplace», depois de visitar a casa presumível do deus da arte e se confrontar com os traços fugidios da Sua existência, desoladamente exclama: «I'll be hanged if He's here!» Stratford é um bom símbolo da irredimível caricatura em que se tornou a situação cultural e a vida museificada da Europa, e já não alcança mais do que servir de poderoso incitamento à tentação velha de nos refugiarmos no texto para, com ele, nos vedarmos a toda a exterioridade, geográfica ou dramática. Talvez este padecimento solicite uma boa dose de medicina chinesa.

Em Xangai, o nome do Bardo terá sido ouvido pela primeira vez nas instituições educativas «extraterritoriais» em que os filhos dos chineses abastados absorveram a língua e a cultura inglesas. $\mathrm{O}$ incipiente modernismo nativo, incubado nesse ambiente, consagrou-lhe esforços pontuais, sobretudo na tradução, mas estes não excederam os limites da casuística cénica ou académica. Só com o advento da República Popular, 
em 1949, se reuniu Shashibiya ao seu destino chinês. As razões terão sido puramente miméticas: Marx e Engels veneravam o Bardo, e o Timão de Atenas, por exemplo, inspirara admiráveis páginas de Marx sobre a natureza do dinheiro. Aquela veneração fora comunicada à grande tradição teatral soviética e, nos primeiros anos da China Popular, a emulação do «irmão mais velho» determinou também os princípios condutores da política cultural. Importou-se a literatura crítica soviética e o estudo do Bardo foi incentivado, sobretudo do ponto de vista da história que o produzira. Na década de 1950, um número de escolas de artes dramáticas foi encorajado a seguir o modelo stanislavskiano e encenadores soviéticos foram convidados a trabalhar nelas como professores. Para a Academia de Teatro de Xangai, uma dessas instituições pioneiras, veio Yevgeniya Lipkovskaya. Shashibiya foi o mediador que permitiu familiarizar os actores chineses com o método stanislavskiano e ilustrar as audiências locais sobre o que poderia ser percebido como autêntico realismo teatral.

Os mesmos ventos da mudança política que tinham favorecido as receptivas velas do shakespearianismo começaram então a soprar adversamente. Após a ruptura com a URSS e a radicalização do maoísmo, Shashibiya foi devolvido à percepção que já inibira o modernismo nativo: a de colosso cultural de um Ocidente corrupto e imperial. Em vésperas da Revolução Cultural, em 1964, o Libertação, publicação governamental de Xangai, dava sinal das nuvens que se aglomeravam: «aqueles que se prosternam no templo de Shakespeare [...] são culpados de favorecer o capitalismo moribundo $»^{2}$. Entretanto, a iminente e longamente preparada publicação das obras completas em mandarim era suspensa. Até à morte de Mao, em 1976, o «feudalista» ou «revisionista» Shashibiya era banido; filmes, encenações e traduções foram interditados, e os intelectuais comprometidos com o Bardo e o seu ensino, humilhados, purgados ou remetidos a campos de reeducação.

Os ventos que impulsionam a fortuna actual de Shashibiya exprimem as aspirações da nova China. Até a transição ideológica ocasionada na morte de Mao, que levaria à redefinição do socialismo e à adopção da economia de mercado, foi buscar ao céu shakespeariano os seus signos premonitórios. Terá sido, com efeito, investido do significado que lhe era conferido pela nova «política das portas abertas» de Deng Xiao Ping, que o directo da última noite da digressão chinesa do Old Vic, com 
Derek Jacobi no papel de Hamlet, prendeu, em 1979, milhões de chineses aos seus televisores. Embora tenha exercido um efeito potenciador, esta digressão correspondia já a um retorno nativo do shakespearianismo. Com a explosão de produções dos anos 80 e 90, o Bardo foi chamado a conformar o ponto de vista de uma China moderna envolvida com a sua história recente, e mesmo a proporcionar-lhe ritos de passagem adequados. Um exemplo é fornecido pelo Much Ado About Nothing apresentado em 1995 no Parque do Huangpo, em Xangai, tendo em fundo, portanto, o mutante skyline do Pudong, já conquistado o estatuto de centro financeiro mundial. A acção, ampliando a notação site-specific, decorria junto do monumento aos heróis da revolução, transmudado, com os seus oitenta degraus, no pátio de Leonato, em Messina ${ }^{3}$. Na memória cultural de Xangai, o valor referencial do Much Ado... era-lhe conferido pela encenação paradigmática de Lipovskaya, em 1959, várias vezes reposta na década de 1980. O início do espectáculo era fiel à convenção historicista do huaju, adoptada por Lipovskaya, com os actores montados em cavalos e involucrados em figurinos italianizantes, próteses nasais e cabeleiras loiras, destinadas a assegurar-lhes aparência caucasiana (o huaju é o drama falado chinês, género herdado do modernismo local e modelado no drama naturalista ocidental). Ao longo da representação, os figurinos evoluíam segundo uma linha de continuidade histórica: perto do fim, eram chineses e actuais. Borachio fugia numa característica bicicleta nativa, mas carregado de dólares norte-americanos. Benedick e Beatrice, em trajes ocidentais, celebravam as suas bodas ao ritmo do disco sound, após o que, junto ao monumento, estacionava o Ferrari que os levaria.

Foi, em suma, junto de um escritor estrangeiro que a China encontrou os recursos com que promover o reencontro ideológico consigo mesma (mais, talvez, do que um encontro com ele). Mais: é o caso prototípico da apropriação da alteridade shakespeariana como modo de construção ou de reforma cultural. Um sintoma revelador é o efeito exercido por Shashibiya na revitalização da tradição xiqu (nome genérico para as mais de trezentas variações regionais do teatro estilizado conhecido fora da China como «ópera chinesa»). Desde a década de 1980 proliferam as adaptações shakespearianas nos subgéneros maiores do xiqu, como o kunju (originário de Suzhou), o chaoxing (de Xangai) e o jingju (de Pequim), o que sem dúvida concorreu para uma expansão das possibilidades 


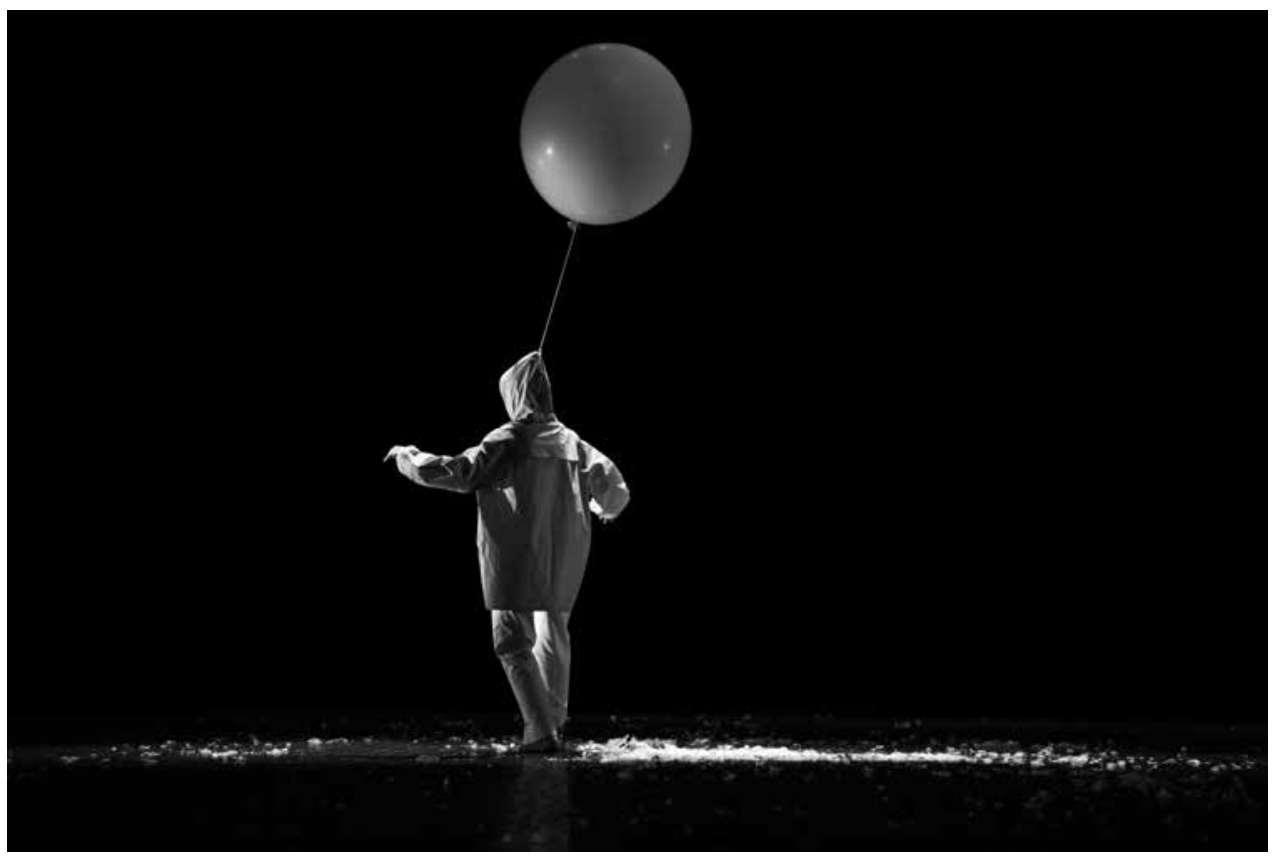

HAMLET, DE William SHAKESPEARE, ENC. CARLOS J. PESSOA, TEATRO DA GARAGEM, 2016 (CAROLINA MANO), [F] ACADEMIA DE TEATRO DE XANGAI

shakesperianas, embora, por exemplo, os solilóquios tenham de ser adaptados aos padrões textuais do drama cantado e a estrutura dramática, ao número convencional de cenas (nove). Mas a administração da medicina alterou radicalmente o médico: Iago ou Hamlet, por exemplo, revelaram-se inapreensíveis na distribuição convencional em caracteres tipo, e a dramaturgia tradicional, por inconformidade do paciente, sofreu modificações de código e de estética. Mas o legado do xiqu shakespeariano é consistente: a condensação metafórica e a estilização «pictórica» dos motivos, uma relação distanciada que, em vez de enraizar a textualidade, parece convidar a sua visualização, uma desidentificação activa de Shakespeare - formas de remediação dramática que, no Ocidente, costumam comparecer com o nome de performance, mas que são imanentes à intuição chinesa do teatro como referido a um tempo único: o presente. É certo que Shakespeare é um veículo de percepção global, e plasmar essa mercadoria fetichizada em formas tradicionais refere-se menos a um confronto local de identidades estéticas autóctones do que à tentativa de as tornar legíveis junto de audiências transnacionais, transformando-as, se possível, em idiomas globais. Cumpriria apurar, em todo o caso, de que modo essa apropriação tem retorno sobre as amplas conotações de um significante («Shakespeare») já de si instável, ou de que modo conjura 
ela possibilidades já in nuce na cosmografia shakespeariana. Sem dúvida, parte do seu interesse provém do modo como, contra a ilusão essencialista de um texto «indivisível», podem revelá-lo comprometido num eterno processo de tradução interna, apto, assim, a todas as solicitações de um encontro genuíno.

Foi no eco destas questões que decorreu, entre 10 e 18 de Setembro últimos, o 9. ${ }^{\circ}$ Festival Internacional de Teatro Experimental de Xangai, formato em vigor na tradição de festivais shakespearianos iniciada na década de 1980, organizado, entre outras instituições, pela Academia de Teatro de Xangai, cujo campus acolheu a maioria das apresentações. Suspeitamos que o qualificativo «experimental» no nome da iniciativa quis exprimir tão-só a extracção diaspórica das produções seleccionadas e a mestiçagem do Bardo em modos performativos percebidas como de «exílio», quer tenham «localidade» cultural ou notifiquem «states unborn and accents yet unknown», como se diz em Julius Caesar (acto III, cena 1). Dezoito produções de catorze países foram convidadas após submissão de projectos em open call (juntando-se a quatro produções chinesas mostradas em programa paralelo). De Portugal, foi o Teatro da Garagem que, à distinção, aliou a coragem: o Hamlet encenado por Carlos Pessoa, exceptuando-se da regra do festival, constituiu uma estreia absoluta, mantendo apenas uma relação arqueológica com a versão apresentada em Lisboa, em 2012 (embora lhe retenha parte do elenco). O tempo costuma avivar a generosidade dos materiais: é por isso mais amável este Hamlet chinês, e mais esclarecido.

Acompanhámos a primeira de duas apresentações. Um público composto sobretudo por estudantes - que asseguraram a organização prática do festival e, divididos em pequenas equipas, contribuíram para a montagem dos espectáculos - lotou os duzentos lugares da Sala Duanjun; muitos professores também, e o público indiferenciado da nova elite cosmopolita de Xangai. Para o mais desprevenido, o comportamento deste público seria alarmante: entradas e saídas da sala, mudanças de lugar, os iPhones obstinados na captação da cena. Tratava-se, porém, dos expansivos hábitos de fruição comuns no Oriente; o elenco compreendeu a medicina e soube, por cima da quarta parede, dar-lhe retorno no seu trabalho; esconjurando as apertadas calamidades de duas vésperas de montagem, pôde então celebrar no lugar adequado a feliz circunstância de se achar na China.

$\mathrm{O}$ que desde logo se recomendou às objectivas digitais foi a solução cenográfica do espectáculo. A cena está eriçada de balões ligados a tubos e contrapesos que, uma vez manipulados, permitem reordenar os valores cénicos em modo mimético (os espaços palacianos) ou alegórico (um balão 
sobressai na quietude dos restantes: é o Espectro). Assumem também valor expressivo: por vezes rebentam, ou os fios que os prendem são, nas contracenas, tangidos e arrebatados; às vezes, têm peso e deixam-se arrastar pelo chão como brinquedos de corda. Confidencia-nos o encenador a alusão a essa terceira forma que, no Oriente, é a estrutura de todas as dualidades: o vazio. De acordo - e reconhecemos a sua notação irónica quando Fortinbras, diminuído pelo enorme balão que traz preso ao capuz, e sugestivo de um teletubbie, aparece para tomar conta de um reino de espectros. Mas somos igualmente sensíveis às circunstâncias imediatas das imagens, e vemos nos balões a esplêndida alegoria das limitações de bagagem, não só nas viagens aéreas, mas também na chamada performance intercultural, quando escolhe meter no bolso balões disponíveis para o ar noutros mundos armazenado. Por causa dos balões, todas as personagens parecem aspirar a deixar-se conduzir pela mão, como crianças, e nisso se denuncia uma certeira intuição dramatúrgica. Com efeito, embora a terrível magnitude das palavras nesta peça pareça apontar-se à execração da ternura, todas as personagens são crianças desvalidas. É essa condição que está contextualizada, em particular, no gracejo que Hamlet dirige a Claudius, afirmando-se «too much i' in the Sun» (I, 2). A homofonia de «Sun» e «son» situa Hamlet na «posição do filho»; e é também neste «too much», nesta «insolação» de ser filho, que a peça se situa, e disso fala sem cessar. Os filhos falam muito da morte dos pais, e o carácter obsessivo do motivo exprime o modo como essas mortes constituem um fardo catastroficamente precipitado sobre a descendência. $\mathrm{O}$ que faz o filho falar é o modo como foge ou não do que é comunicado nessa catástrofe, o modo como se cumpre o que ela põe em jogo, como se prolongam ou extinguem os seus efeitos. Os órfãos, a contas com o que os desvalida, procuram vingar-se ou enlouquecem, mas apenas para consumarem o mesmo destino dos pais. Declara Claudius, no início, que os pais morrem sem consequências, «and it is as common as any the most vulgar thing to sense» $(\mathrm{I}, 2)$. Não é verdade: correm em Elsinore torrentes de sangue, e só para refutá-lo.

Usou-se a tradução de José Blanc de Portugal, aqui e ali rescrita pela equipa para servir transições necessitadas nos cortes de texto: é funcional e, às vezes, elegante. A este respeito, limitamo-nos a observar, sem mais adesões, que a tradução do Hamlet - demasiadas vezes regida por musas menores e quase sempre imprestável para o palco - permanece ainda hoje uma questão em aberto no panorama português. Já os cortes expurgam o texto de Guildenstern e Rosencrantz, e abreviam cenas e solilóquios: exprimem, naturalmente, um foco dramatúrgico e uma identidade 
performativa. Na peça, o único acto de Hamlet é a contínua inverificação - tematizada sem cessar - do acto a que se propõe. Esta moratória do acto contamina-se a todas as personagens, tal como as mortes que lhes cabem (sempre com o endereço errado) são a epidemia de uma morte original. A opção dramatúrgica instala esta consciência «em negativo», ao reter quase só as acções, tão condenadas ao esvaziamento como os balões, e rarefazendo as palavras (ou mostrando-as, literalmente, como balões).

A questão da forma da acção em Shakespeare suscita-nos algumas observações genéricas sobre o trabalho do actor. Shakespeare participa de um fundo essencial de experiência que escapa, por exemplo, ao sistema de autorias que funda a história literária e que só o qualificativo «mítico» pode devolver na sua ligação primária a uma realidade comungada. Como mito elementar, o texto é, em Shakespeare, a forma da acção (no caso de Hamlet, é a acção que sintetiza a desafectação de toda a acção). E tal como a acção, a cada passo, excede os princípios com que tentamos governá-la, assim excede o texto o processo de controlo do elocutor. As personagens de Shakespeare estão em permanente escuta de si mesmas e, portanto, em decifração do que dizem, porque o que dizem não é produto da introspecção: é antes o modo como a si mesmas se criam e em si mesmas se tornam presentes enquanto criação (razão por que mais depressa nos disporíamos a rever o Hamlet de Mel Gibson, apesar do intolerável filme que protagoniza, do que Laurence Olivier e os seus perniciosos duzentos anos de controlo crítico incorporados como linguagem protocolar do actor). Só assim é possível restituir o trabalho do actor à dimensão de mito elementar que lhe assiste. Nesta dimensão, só é actor aquele que é reconstruído pela sucessiva reiteração do acto. Ao longo dos anos, com afinidade, temos lido no trabalho da Garagem a segura indicação da primazia do acto sobre o actor, de que depende, em última análise, a redenção deste último.

Sentada a nosso lado, na sala da Huashan Lu, uma senhora de Xangai, inteirada, em inquérito prévio, da nossa nacionalidade, e particularmente emocionada com a aparição de Fortinbras, fez-nos mediador de agradecimentos que retribuíam, segundo declarava, uma bela homenagem à China. 